\title{
Bağlanma Teorisi ve Bağlanma Bozukluklarına Genel Bir Bakış
}

\section{Attachment Theory and an Overview of Attachment Disorders}

Öz

Bağlanma sistemi, bebeğin hayatta kalması için hayati önemi olan, sadece insana özgü olmayıp doğada bütün memeli türlerinde görülen evrimsel bir sistemdir. Anne-çocuk ilişkisinden başlayarak kişinin hayatı boyunca kurduğu bütün ilişkiler için bir taslak arz eden bağlanma biçimi, kronik hastalık durumlarında kişinin tedavi ekibi ile kurduğu ilişkide de belirleyici olabilmektedir. Bağlanma temelde güvenli ve güvensiz bağlanma olarak ikiye ayrılır; güvensiz bağlanma ise kendi içinde kaygılı, kaçıngan, ve dezorganize güvensiz bağlanma olmak üzere üç tiptir. Güvenli bağlanma özellikleri göstermeyen kişiler, bazen sorunlu ilişki kurma biçimleri nedeniyle "zor hasta" olarak tanımlanarak klinik ilgi odağı olmaktadırlar. Bağlanma biçimleri ve bunlardan kaynaklanabilecek sorunlar literatürdeki bilgiler ışığında incelendiğinde, basit birtakım girişimlerin doktor-hasta ilişkisindeki bazı zorluklara çözüm olabileceği görülmektedir. Hastaların farklı bağlanma biçimleri dikkate alınarak ve tedaviler hastalar ile işbirliği içinde planlanarak, hastalara kişiye özgü ve daha başarılı bir bakım sağlanabilir. John Bowlby tarafından temelleri atılan bağlanma teorisi ile ilgili bilgi sahibi olmak ve hastaların farklı bağlanma biçimlerini tanıyabilmek terapötik işbirliğinde nerede olduğumuzu görmemize ve doğabilecek sorunları öngörerek daha iyi sağılı hizmetleri vermemize yardımcı olabilir.

Anahtar Sözcükler. Bağlanma; tedaviye uyum; zor hasta

\begin{abstract}
Attachment system is an evolutionary system that is seen in all mammals in nature and vitally important for the baby's survival. The attachment pattern developed in the infancy functions as a template for all relationships in life beginning with the first interaction between the mother and baby, and may play a decisive role in the relationship that one forms with healthcare professionals in case of chronic illness as well. Attachment patterns can be distinguished as secure and insecure attachment; and insecure attachment can be further categorized into three patterns: anxious, avoidant, and disorganized insecure attachment. Patients who do not exhibit a secure attachment pattern sometimes become the focus of clinical attention as "difficult patients" due to their problematic forms of developing relationships. When attachment patterns and the related problems are investigated in the light of the literature, it is seen that solutions for such problems in the doctor-patient relationship are possible by certain simple interventions. Individualized, more successful healthcare can be achieved by considering patients' distinct attachment patterns and cooperating with the patient in planning the treatment. Being knowledgeable with the attachment theory founded by John Bowlby and able to recognize patients' distinctive attachment patterns might help us realize where we stand in the therapeutic collaboration with the patient and, enabling us to anticipate potential problems, can result in better healthcare.

Keywords: Attachment; treatment compliance; difficult patient
\end{abstract}

\section{Eren Yıldızhan}

Sağlık Bakanlığı Prof. Dr. Mazhar Osman Ruh Sağlığı ve Sinir Hastalıkları Eğitim ve Araştırma Hastanesi, Psikiyatri Bölümü , İstanbul, Türkiye
Geliş Tarihi /Received : 09.06.2016 Kabul Tarihi /Accepted: 21.11.2016

DOI: 10.21673/anadoluklin.237462

Sorumlu Yazar/Corresponding Author Uz. Dr. Eren Yıldızhan

Sağlık Bakanlığı Mazhar Osman Ruh Sağlığı ve Sinir Hastalıkları Eğitim ve Araștırma Hastanesi, Psikiyatri Bölümü,

14. Psikiyatri Servisi, H1-B, 34147 ,

Zuhuratbaba, İstanbul, Türkiye

E-mail: erenyildizhan@hotmail.com 


\section{Gíiş}

Bağlanma teorisi kişinin hastalık gibi bir stres durumunda neler hissedeceğini, nasıl tepki göstereceğini anlamada ve hekimlerin bu stresle baş etmede nasıl yardımcı olabileceğine yol göstermede yardımcı olur. Konsültasyon-liyezon psikiyatrisi başta olmak üzere bütün hekimlerden hastalığı olan kişiye psikolojik destek sağlaması istenir. Her kişinin hastalığa reaksiyonu kendine özeldir.

$\mathrm{Bu}$ makalede hastalığın bir stres modeli olarak kişinin karakteristik bağlanma biçimlerini aktive etmesi ve hastalığa karşı davranışlarını etkilemesi üzerinde durulacaktır. Öncelikle bağlanma teorisi genel hatlaryyla gözden geçirilecek, daha sonra değişik bağlanma biçimlerinin hastanın davranışını nasıl etkilediği ve her bağlanma stiline göre özel yaklaşım tarzları açıklanacaktır.

Bağlanma teorisi II. Dünya Savaşı sırasında John Bowlby tarafından bebekler ile birincil bakım veren ebeveynleri arasındaki etkileşim biçimlerinin gözlemlenmesi sonucunda oluşturulmuştur (1). Bowlby yetişkinlerde hastalık sırasında bağlanma ilişkisinin önemine dikkat çekerek, bağlanma ihtiyacının hastalık ve benzeri olaylar (doğum, ayrılık, ölüm, organ kaybı, görme kaybı gibi) tarafından aktive edilebileceğini ifade etmiştir (2-4). Bununla hastalıkta kişilerin yakın önemli figürlere ihtiyacının artacağı ifade edilmektedir. Bu ihtiyaç ve onun ortaya çıkardığı davranış şekilleri bazen hastanın tedavi ekibi ile ilişkisini olumsuz etkileyebilir; "zor hasta" olarak tanımlanan hastaların bazılarının zorluğu tedavi ekibi ile kurulan ilişkiyi bozan bağlanma biçimlerinden kaynaklanmaktadır. $\mathrm{Bu}$ olayın iyi anlaşılması, hastalıkla ilişkili stresin üstesinden gelmede hekime yardımcı olabilir.

\section{BAĞLANMA BIÇIMLERI}

Bağlanma sistemi, doğada bütün memeli türlerde görülen, doğuştan var olan, bağımsız hareket etme kapasitelerinden yoksun olan yenidoğanın hayatta kalmasını sağlayan evrimsel bir sistemdir (5). İki temel amacı vardır. İlki bağlanma figürüne yakınlığın sürdürülmesi ile tehlikelerden korunmak, ikincisi ise bağlanma figürünün verdiği güvenle etrafı bağımsız olarak keşfetmeyi sağlamaktır. Bağlanma davranışları (ağlama, izleme, tutunma, aksileşme gibi) genellikle primer bağlanma figürünün beklenmeyen ani yokluğu veya yeni tehdit edici bir uyaran gibi tehdit hallerinde ortaya çıkar (2). Bağlanma ilişkisi biçimleri çeşitli şekillerde gruplaştırılabilir. Bowlby bu paternlerin yaşam boyu sürmesini internal working model (içsel çalışma modeli) ile açıklamıştır (6). Bu model tehdit esnasında kendisinin ve diğerlerinin olası davranışlarını tahmin ederek ona göre uygun davranışı belirlemeyi sağlayan bir bilişsel şema olarak tanımlanabilir. Kişilerin bağlanma biçimleri karakter özelliklerinin bir parçasını oluşturur ve ayrılık, kayıp gibi bağlanmayla ilgili belirli durumlarda daha açık ortaya çıkar.

Bağlanma ilişkisi biçimleri birçok değiş̧ik şekilde sınıflandırılmıştır. Genellikle çalışmaların çoğunda Hazan ve Shaver tarafından geliştirilen kendini değerlendirme ölçeği ile belirlenen sınıflama kullanılmaktadır $(7,8)$. Bu sınıflamada birincil ayırım, güvenli bağlanma ilişkisi (secure attachment) ile güvensiz bağlanma ilişkisi (insecure attachment) arasında yapılmıştır; güvensiz bağlanma ise kaygılı bağlanma (anxious attachment) ve kaçıngan (avoidant attachment) bağlanma olarak ayrılmıştır. Güvenli bağlanma ilişki biçimine sahip olan kişi bağlanma figürlerinin (başlangıçta ebeveynler, sonra eş veya yakın ilişkide olduğu kişiler) tehdit anında etkili ve güvenilir olacağı inancına göre davranış sergiler. Toplumun yaklaşık \%55'inde bu tür bağlanma biçimi görülür (8). Güvensiz endişeli bağlanma ilişki biçimine sahip olan kişilerde olayların üstesinden geleceklerine dair kendilerine ve çevrelerine inançları yetersiz olup güç durumlarda diğerlerine kaygılı ve saplantılı tutunma şeklinde yaklaşırlar. Gelişimsel deneyimlerinde ihtiyaç sinyallerini devamlı sürdürmeleri halinde bağlanma figürünün yanlarında bulunduğunu deneyimlemişlerdir. Bundan dolayı kompülsif bakım arayan davranışlar geliştirmişlerdir (9). Bu bağlanma ilişki biçimi için kaygıll, bağıml, impulsif, onay arayan (anxious, dependent, impulsive, approval-seeking) terimleri de kullanılmaktadır (10). Bu kişilerde duygulanımın ifadesi yoğun olup, diğer kişilerde endişe toleransının zayıf olduğu izlenimini uyandırır. Güvensiz-kaygılı bağlanma ilişki biçiminin prevalansı yaşla birlikte azalmakta ve çalışmalarda yaklaşık \%20 olarak bulunmaktadır $(8,10)$.

Güvensiz-kaçıngan bağlanma ilişki biçimine sahip olan kişiler erken dönemde ihtiyaçları olduğunda bakım veren kişinin uzak, güvenilmez ve yakınlıktan 
hoşlanmayan tutumlarına maruz kalmışlardır. Stres durumunda diğer kişilerin yardımcı olacağı fikrine inanmazlar ve saplantılı bir biçimde kendi kendine yetme çabası sergilerler. Bu bağlanma biçimi bazı kaynaklarda, kaygı halinin ve bağlanma ilgisinin az olmasına vurgu yapmak amacıyla kayıtsız bağlanma olarak da tercüme edilmiştir (11). Diğer kişiler tarafından soğuk ve yarışmacı, duygularını ifade etmeyen ve çok kontrollü olarak tanımlanırlar $(9,10)$. Prevalans toplum çalışmalarında yaklaşık \%15 olarak gösterilmektedir (8).

Bağlanma benlik ve başkaları ile ilgili tutumlar perspektifinden incelendiğinde, güvenli bağlanmada olumlu benlik ve olumlu başkaları, güvensiz-kaçıngan bağlanmada olumlu benlik ve olumsuz başkaları, güvensiz-kaygılı bağlanmada olumsuz benlik ve olumlu başkaları olduğu belirtilmekte, olumsuz benlik ve olumsuz başkaları modeli ise güvensiz-korkulu bağlanma olarak tanımlanabilmektedir (12). Başka bir şekilde ifade edilirse; başkalarına bağımlılığı ve başkalarından kaçınması az olanlar güvenli bağlananlar ("yardıma ihtiyacım olabilir ve yardım bulabilirim"), başkalarına bağımlılığı fazla olan fakat başkalarından kaçınması az olanlar kaygılı (preoccupied/ambivalent/ anxious) ("kendim asla yapamam; ancak yardımla olabilir”), başkalarına bağımlılığı az olan fakat başkalarından kaçınması fazla olanlar kaçıngan (dismissing/ avoidant) bağlananlar ("yardım gelmeyecek ve zaten gerek yok”), başkalarına bağımlılığı fazla olan ve başkalarından kaçınması da fazla olanlar korkulu (fearful) bağlananlar ("kendim yapamam ve yardım da gelmeyecek”) olarak tanımlanmaktadır. Korkulu bağlanma biçimi, kaygılı ve kaçıngan bağlanma biçiminin elementlerini içermektedir, kişi duygusal yakınlığa çok gereksinim duyduğuna inanmasına karşın reddedileceği ve yüzüstü bırakılacağına olan inancı ve kendine güvensizliği nedeniyle bu yakınlık onu korkutur (13).

Bağlanma alt tipleri bir spektrum olarak doğrusal bir şekilde de gösterilebilir. Spektrumun bir ucunda aşırı duygusal dışavurumu olan (duygulanım düzenleme zayıflı̆̆ı), diğer ucunda ise duygusal dışavurumda yetersizlik (duygulanımın aşırı düzenlenmesi ve kontrolü) olan grup yer almaktadır. Bu spektrumda, güvenli bağlanma ortalarda yer alır. Kişinin bu spektrumda nerede yer alacağı önceki deneyimlerine, özelliklede ilk bağlanma figürü ile olan deneyimlerine bağlıdır.

Bağlanma biçimlerinin doğrusal modeline göre güvenli bağlanma orta derecede duygulanım regülasyonunu ve dışavurumunu birleştirir. Kaçıngan bağlanmada aşırı duygulanım regülasyonu ve duygulanım dışavurumunda yetersizlik, endişeli bağlanmada ise duygulanım regülasyonunda yetersizlik ve yüksek duygulanım dışavurumu görülmektedir.

Kişilerin çoğu bu spektrumda herhangi bir noktaya uyabilir. Bu gruplara uymayan kişileri tanımlamak için diğer bir bağlanma grubu tanımlanır: dezorganize grup (insecure- disorganized group). Dezorganize bağlanma spektrumda tutarsız biçimde herhangi bir yerde olabilir. Bu grubu tanımlamak için önce bağlanma ile ilgili kavramlardan biri olan tutarlılıktan söz etmek gerekir; Main, geliştirdiği Erişkin Bağlanma Değerlendirme Formu (Adult Attachment Interview-AAI) ile bu kavrama dikkat çekmiştir ve bu form erişkinlerin bağlanma ilişkisi biçimlerini kategorize etmekte kullanılmaktadır (14). Bu değerlendirme formunda kişinin geçmişi ile ilgili verdiği bilgilere değil bu soruları yanitlama stillerine dikkat edilmektedir. Tutarlı bir görüşmede kişi geçmişi ile ilgili birçok olaydan rahatlıkla bahseder ve o sıradaki duygulanımı anlattığ ile uyumludur. Hatıralarda ufak kesintiler olsa da diğer kişilerin tanımı ayrıntılı ve yeterlidir. Tutarsız bir görüşmede ise hatırlamalar sık sık bölünür, amnezilerden bahsedilir, diğer kişilerin tanımlanması yetersizdir ve genel bir tanımla sorular geçiştirilmeye çalışılır, "Babam mükemmel bir insandı" gibi. Böyle bir tanım diğer anlatılanlarla doğrulanamadığı gibi terkedilme, cezalandırma gibi sık sık tersini gösteren anlatımlar fark edilir. Bağlanma ile ilgili diğer bir kavram, Main’in "meta-bilişsel gözlem" (meta-cognitive monitoring) veya Fonagy'nin "yansitma işlevi" (reflective functioning) olarak adlandırdığı kavramdır $(14,15)$. Tutarlı görüşme yapılabilen kişiler tipik olarak kendilerinin ve ilişkide oldukları diğer kişilerin ruhsal durumunu izleyerek üzerinde düşünürler. Yansıtmalı gözlem işlevi (the reflective [monitoring] function) kişiye kendisinin ve diğer kişilerin psikolojik deneyimlerini dikkate alarak, diğerinin deneyimlerine dahil olup diğerinin aklını anlamasını sağlar (16). Güvensiz bağlanma biçimine sahip kişiler diğerlerinin ihtiyaçları karşısında tutarsız, azarlama ve reddedilmelerle dolu inançlarından dolayı diğer kişilerin ne düşünüp hissettiklerini anlamada güçlük yaşarlar (16). Bundan dolayı bu kişiler, kendilerinin ve diğer kişilerin içsel yaşantıları 
üzerine yoğunlaşmada başarılı değildirler. Bu durum şimdiki ilişki biçimlerinde ve aile ilişkilerinde belirgin olarak ortaya çıkar.

Dezorganize bağlanma klinik olarak üzerinde düşünme kapasitesinde düşüklük, anlatılan öykülerde belirgin tutarsızlık olarak ortaya çıkar. Dağınık biçimin görüldüğü kişiler baskın olarak kaygılı ya da kaçıngan biçimi kullanıyor olsalar da stres altında bu iki biçimin karışımını sergileyebilirler. Hem yaklaşma, tutunma, hem de kaçınma, uzak durma davranışı gösterebilirler. Dağınık bağlanma biçimi gösteren kişilerin özgeçmişinde psikolojik travma hikayesine sıklıkla rastlanır (17). Erken ilişki biçimleri problemli olup tutarlı bir şemaya sahip olamadıklarından ilişkilerinde bazen yardım arayan, bazen güvensiz ve uzaklaşan olarak bocaladıkları fark edilir.

$\mathrm{Bu}$ prensiplerin klinikte hasta yönetiminde uygulanmasına girmeden önce, bağlanma biçimlerinin doğasını ve dinamiklerini anlamanın klinik değerlendirmede girişimi belirlemeye değil, girişim hakkında bilgilenmeye yardımcı olduğunun altını çizmeliyiz. Bağlanma teorisi hastayı formüle etmede veya faydalı girişimlerde bulunmada farklı bir bakış açısı yaratarak hastayı değerlendirmede ve uygun yaklaşımı bulmada yardımcı olur.

Bağlanma teorisinin konsültasyon-liyezon hekimliğinde, özellikle de yatan hastalarda çok işe yaradığ 1 bildirilmektedir (18). Daha öncede bahsettiğimiz gibi hastalık bağlanma sistemini aktive eder. Hastalığın yarattığı stres dışında hastaneye yatış; yeni bir ortama girmeyi, önemli kişilerden ayrılmayı, bilmediği kişilere kendini emanet etmeyi ve yeni hasta rolüne bürünmeyi içerir ki bunların hepsi bağlanma stresi oluşturur (19). Bağlanma biçimleri ve hastalık yaşantısındaki etkileri ile yaklaşım farklılıklarından burada bahsedeceğiz.

\section{Güvenli Bağlanma}

Erken çocukluk dönemlerinde yeterli bir bakım görmüş ve birincil bakım veren sorumluluk sahibi ebeveynleri ile güvenli bir bağlanmaları olmuş olan kişiler hastalık nedeniyle sıkıntıya girseler de toparlanacakları duygusunu yaşarlar (13). Bu kişilerin içsel çalışma modeline göre beklentileri yeterli yardım alacakları, kriz anlarında tedavi ekibine güvenilebilecekleri şeklindedir. Hastalık nedeniyle oluşan kaygı, korku, öfke gibi diğer olumsuz duygulanımlar bakım veren kişileri uzaklaştırmayacak, bıktırmayacak şekilde ifade edilir. Kendi hastalıkları ve durumları hakkındaki derin düşünme ve anlamaya ek olarak, çevrelerindeki kişiler ve çalışanlar üzerindeki etkilerini de değerlendirebilirler. Hastalık olarak kötü durumda olsalar da yardım edilmesi zor olmayan kişilerdir.

\section{Güvensiz-Kaygılı Bağlanma: Saplantılı Yardım Arayışı}

Erken çocukluk döneminde ebeveynlerinden siklıkla tutarsız, çoğu kez aşırı koruyucu bir bakım görmüş olan kaygılı bağlanma biçimine sahip kişiler, hastalıkla başa çıma kapasitelerinin çok düşük olduğuna inanırlar (13). Doktor veya hemşire olduğunda biraz yatışırlar; fakat onlar ayrılınca sakin kalmada güçlük çekerler. Bu hastaların içsel çalışma modeline göre bağlanma figürlerine yakın olmanın en iyi yolu devamlı stres sinyali göndermektir. Bundan dolayı hastalık sırasında tedavi ekibini devamlı olarak kendileri ile meşgul etmeleri gerektiğine inanırlar. Yakınma ya da şükran ifadeleri ile bakım verenleri yanlarında tutmak mümkün olmadığında sedüktif davranışlar, açı yalvarma, aşırı övme gibi yeni stratejiler üretilir (20). Bu devamlı bakım arama paterni kişinin kapasitelerinin yetersiz olduğuna dair içsel inancı sonucunda devamlı başkalarına yaslanmayı, fakat verilen yardımı yetersiz bulmayı, çevresindekileri devamlı bir sıkıntı içine sokmayı ve sakinleşebilmek için doyurulamayan bir yardım arayışını doğurur.

Hastanın kendi içsel korkusu ile aşırı meşguliyeti nedeniyle diğerlerinin ruhsal durumunu değerlendirmesi oldukça kısıtlanmıştır. Tıbbi personel tarafından bu hastalar "mızmız," "yapışkan” olarak değerlendirilebilirler. Eğer hasta, personelin bu yaklaşımlarını anlarsa güvensizlik ve kaygı duyguları daha da artar. Hastalara yaklaşımda sınırların iyi konulması, bu limitler içinde empatik bakım verilmesi ve ihtiyaçların karşılanması önerilir. Örneğin somatize etme eğilimi olan hastalar için 15 dakika süreli düzenli aralıklı vizitler veya iki saatte bir 10 dakikalık düzenli hemşire vizitleri uygun olabilir (21). Buradaki amaç hasta sormadan temin etmek, böylece hasta yakınsa da yakınmasa da yardım olacağ 1 düşüncesini desteklemektir. Ayrıca devamlı ihtiyaç içinde, sıkıntılı olan hastaya yardımcı olabilmek için tedavi ekibi dışsal düzenleyici-kapsayıcı görevi yaparak hastanın stresini kontrol altına almaya çalışmalıdır. İyi bir düzenleyici görevi 
için güvenilir, tutarlı, kararlı ve ilgili olmak gerekir. $\mathrm{Bu}$, zamanında işini yapmayı, hasta yanında belirlenen süre kadar durmayı, hastaya yönelik uzak durma isteği şeklindeki karşı aktarımına karşı koyabilmeyi gerektirir. Stres sinyallerini yatıştırmanın en iyi yolu, ilk akla gelenin aksine, çağrılmadan ilgilenmek ve hastadan uzak kalmamaktır. Bu hastalar doğrusal dağılımın en uç bölgesinde yer alırlar, onların ana sorunu duygulanım düzenleme bozukluğu olup hekimin bu konuya önem vermesi gerekir. Duygusal stresin etkili dışavurumsal düzenlenmesi için hem psikoterapötik hem de psikofarmakolojik girişim gerekebilir. Tedavi ekibinin beraber ve bir bütün olarak hareket etmek için kendi içinde ve hasta ile toplantılar yapması yararlıdır. $\mathrm{Bu}$, yanlış değerlendirilmeleri ve bölünmeleri engellemeye yardımcı olur, terapist olmadığında diğerlerinin dışsal düzenleme görevi yapmalarına olanak tanır. Farmakolojik olarak hastaların kaygısını azaltmak için duygulanım regülasyonunda yardımcı olan ilaçları, anksiyolitikleri vermek faydalıdır.

\section{Güvensiz-Kaçıngan Bağlanma: Zorlantılı} Kendine Yeten Hasta

Kendine yeten izlenimi veren, kaçıngan bağlanmas1 olan hastalar talep belirtmedikleri için tedavi ekibi tarafından problemsiz kişiler olarak değerlendirilir. Erken çocukluk döneminde çoğunlukla sorumsuz ve ilgisiz ebeveyn bakımına maruz kalmıs, en iyi stratejinin kendi kendine yetmek olduğuna olan inançları sağlamlaşmış olan bu kişilerin içsel çalışma modelleri diğer kişinin güvenilir olmayacağı, kendi işini kendi yapmanın daha iyi olacağı, her türlü bağlılık durumundan uzak durmanın ihtiyaç halinde zaten bu kişileri bulamayacağı için en iyisi olduğu şeklindedir (13). Fakat büyük bir hastalıkla kısıtlandıklarında bu tercih ettikleri stratejiyi uygulayamayınca sorun başlar.

İyi bir anamnez bu ilişki biçiminin anlaşılmasında yardımcı olur. Görüşme sırasında çok az duygu ifade edilir, olayları ve yaşamları hakkında çok az bilgi verirler. Hastalıklarının sonuçlarının riskini düşük değerlendirme çabasındadırlar, empatik girişimi reddederler, diğerlerine ihtiyaçları olduğu fikrini reddederler. Örneğin empatik açıdan yetersiz oldukları için eşlerinin üzüntülerini anlamazlar. Bu kendine yetmeye yönelik aşırı çaba birçok sorun yaratabilir. Doktor veya hemşirenin yaklaşım girişimleri tehdit edici, k1sıtlayıcı olarak algılanır. Genel anestezik veya narkotik kullanımı ile oluşabilecek kontrol kaybı durumlarına direnebilirler. Aşırı bağımsız olma çabaları tıbbi tedaviye uyumsuzluğa yol açabilir, ilaçları kendi bildiği gibi almaya kalkarak aksatabilir veya hareket ettirmemesi gereken organlarını hareket ettirerek tedaviyi zorlaştırabilirler. Diyabeti olan hastalar ile yapılan araştırmalarda bu bağlanma biçiminin HbAlc seviyeleri, ayak bakımı, diyet ve tedavi uyumu gibi birçok alanda, depresyonun etkileri dışlandıktan sonra bile daha kötü sonuçlar ile ilişkili olduğu gösterilmiştir (22). Ayrıca, kanser tanısı alan hastalardan kaçıngan bağlanma biçimi olanların sonradan daha fazla psikolojik sıkıntı yaşadıkları ve sosyal ilişkilerinde daha fazla sorun ortaya çıktığı gösterilmiştir (23).

İyi bir yaklaşım ve terapötik ilişki için hastanın bağımsız olma ihtiyacına saygı duymak gerekir. Hastanın mesafe koyma çabasına mümkün olduğunca izin verilebildiğinde, bağımlı olma kaygıları nedeniyle daha fazla uzaklaşma girişimleri engellenebilir. Arkadaşça doktor-hasta ilişkisi yaklaşımı burada tamamen yersizdir; aksine daha empatik olan yaklaşım onların uzak olma isteğine, kişisel kontrolü ellerinde tutma isteğine saygı duymaktır. Dikkat edilecek temel birkaç nokta, hastaya resmi hitap etme, hasta yatarken düşkün ve hasta olduğunu vurgulamasın diye ayakta durma, mümkün olduğu kadar çabuk taburcu etme olabilir.

Psikoterapide bu kişilerde dirence sık rastlanır (24). Özellikle ilişkileri ile ilgili açıklamalar hastaları kaygılandırıp kaçınganlıklarını artırarak terapistle ilişkiyi engellemelerine neden olabilir. Hastane ortamında doğrudan ilişki biçimi üzerine yoğunlaşmak hastayı uzaklaştırabileceği için tavsiye edilmez. Fakat diyabet gibi kronik hastalıklarda hasta ile sürekli bir ilişki gerektiği için bu ilişki tarzında değişiklikler yapmak gerekir. Böyle durumlarda zamanla duygulanım kontrolünün azaltılmasına cesaret vermek, duygusal durumu belirleyip spektrumun ortasına çekmeye çalışılmak uygun olacaktır. Bu yaklaşım kuşatılmışlık hissini azaltarak hastanın kendi duyguları ve yaşamı hakkında meraklanmasına ve düşünmeye sevk edilmesine yol açacağından yararlı olur.

\section{Dezorganize Bağlanma}

Dezorganize bağlanma stiline sahip hastalar, çocuklukta bakım veren kişi ile çok problemli ilişki deneyimleri yaşamışlardır. Bakım veren zarar verici, kötüye 
kullanıcı olabilir (17). Çoğunlukla kaotik, travmatik çocukluk deneyimleri olan bu kişilerin içsel çalışma modelleri diğerleri ile ilişki geliştirmede güvenilir bir stratejiye sahip değildir. Görüşmede bu yüzden tutarsızlığa, öykü almakta zorluğa, alınan öyküyü anlamada güçlüğe sık rastlanır. Duygulanımsal yaşantıları yoğun gibi görünse de tutarsız ve çözünmeye meyillidir (16). Hastayı rahatlatma çabaları genellikle etkisizdir. Reflektif fonksiyonları yetersiz olup, çoğu zaman kriz ruh durumunda oldukları için buna hastalık eklenince bu durumları daha da abartılı hale gelir. Bu hastalar tıbbi ekibin güvenilir ve etkili girişimine ihtiyaç duymakla birlikte buna olan güvenleri çok azdır. Kendi sağlıkları ile ilgili aşırı kaygıları diğerlerine olan güvensizlikle birleşince bakım verenlere ve tedavi ekibine daha çok ilgi için baskı yaparlar. Aynı zamanda reddedici bir tavır içine girip, bağımlı role geçmeleri nedeniyle duydukları öfkenin pasif ifadesi yoluna giderler. $\mathrm{Bu}$, abartılı ve hipokondriyak bir yardım arama davranışı geliştirmelerine ve aynı zamanda öfkelerini işlevsel olmayan bir biçimde ifade etmelerine yol açar. Bu hem yardım isteyen hem de reddeden çifte mesajlı durum tedavi ekibinde yoğun öfke yaratır.

Sağaltım hedefi burada hastayı doğrusal çizgide ortalara çekmek olmalıdır. Yapılması gereken hastanın dağınıklı̆̆ını tedavi ekibine yansıtmasını önleyerek ekibin dışsal düzenleme-kapsama ve bakım veren rolünü sürdürmesini sağlamaktır. En azından "bu yer kendi kurallarına göre hareket eder" mesajı güvensizliği ve tehdit beklentilerini azaltabilir. Kendi ruhsal süreçleriyle ilgili düşünme kapasiteleri az olduğu için içsel çatışmalarına yönelmenin faydası olmayabilir. Saldırgan eğilimi kabul etmek fakat öfke ifadelerine sınır koymak önemlidir. Bu tür hastaların yapılanlara klasik anlamda şükran duymayacağını, şükranlarını sadece tedavi ekibini rahat birakmakla ifade edeceklerini önceden kabul etmek de beklentileri düşürmek açısından önemlidir. Tedavi ekibinin arasını açabileceği inancı, ekibin birbirlerini suçlaması ya da öfke belirtisi olarak ekibin tedaviyi aksatması, hastanın kaygı ve yanlış inançlarını destekler, eyleme koymalara yol açar. Ayrıca hastaların, sık ve sürekli yakınmaları nedeniyle gereksiz tıbbi incelemelere maruz kalma tehlikeleri de vardır.

En faydalı strateji bilinen genel standart tedavi prensiplerine bağlı kalmaktır. Hastanın yarattığı öfke nedeniyle erken taburcu edilmemesine veya gereksiz araştırmalara girilerek daha uzun hastanede tutulmamasına dikkat etmek gerekir. Bir yandan hastanın bulunduğu zor duruma üzülerek duyulabilecek onu kurtarma isteği, bir yandan duyulan öfke nedeniyle ölmesine dair çoğu kez bilinçdışı arzular, tedavi eden hekimi zor durumda bırakabilir. Dezorganize bağlanma biçimi olan hastalar tedavi ekibinde şiddetli başarısızlık hisleri uyandırabilir, bu durum daha fazla yardım etme isteğiyle profesyonel sınırların aşılması tehlikesini de ortaya çıkarabilir. Bazı ileri derecede dağınık vakalar, tedavi ekibindeki kişileri bağlanma sistemlerindeki değişken ve çatışmalı roller içine sokabilirler. Bir kişi bütün bağlanma ihtiyaçlarının yansıtıldığı, bağlanma isteği uyandıran bir figür olarak, diğer bir kişi öfke yaratan yetersiz bağlanma figürü olarak, bir diğeri ise yıkıc1, tehdit oluşturan, güvensizlik hissettiren ve kaçınma isteği uyandıran bir figür olarak bölünebilir. Tedavi ekibi ile daha fazla zaman geçirilmesine olanak tanımak bu yoğun olumsuz duygularla baş edilmesine yardımcı olabilir. Ekip toplantısı; iletişim sağlanması, hastaya karşı oluşan olumsuz reaksiyon ve öfkenin ifade edilmesi, ekibin destekleyici ortamda olumsuz duygularını dışarı vurması yolu ile hem ekip üyelerinin rahatlamasına hem de bu olumsuz duyguların hastaya yansitılmasının önlenmesine yol açacağından yararlıdır. Ekibin çok sayıda kişiden oluşması, hastanın belli kişileri belli figürlere bölmemesi açısından faydalı olur. Dezorganize bağlanması olan hastalar için kriz hallerinde ruh sağlığı servislerine ulaşımın kolay ve hızlı olması gerektiği unutulmamalıdır.

\section{SONUÇ}

Bağlanma süreçleri terapötik ilişkide önemli bir yere sahiptir. Tedavi ekibine güçlük çıkardığı ya da tedavisine uymadığı için sürekli olumsuz sağaltım sonuçlarıyla klinik ilgi odağı olan hastaların bu durumunda, birçok kez bağlanma biçimlerindeki sorunların rol oynadığı akılda tutulmalıdır. Hastaların bağlanma biçimlerini anlamak, tedavi ekibini karşılaşabilecekleri sorunlara önceden hazırlayabildiğinden, hem bu sorunların çözümü ile ilgili önlem alma fırsatlarını artırabilir, hem de etkisiz olan yaklaşımların tekrarlanmasını önleyerek tedavi ekibinin yıpranmasını azaltmaya yardımcı olabilir. 


\section{KAYNAKLAR}

1. Bowlby J. The making and breaking of affectional bonds. II. Some principles of psychotherapy. The fiftieth Maudsley lecture. Br J Psychiatry. 1977;130:421-31.

2. Bowlby J. Attachment. New York: Basic Books; 1969.

3. Bowlby J. Separation: Anxiety and Anger. New York: Basic Books; 1973.

4. Bowlby J. Loss: Sadness and Depression. New York: Basic Books; 1980.

5. Kraemer GW. A psychobiological theory of attachment. Behav Brain Sci. 1992;15(3):451-93.

6. Bretherton I, Munholland KA. Internal working models in attachment relationships: a construct revisited. Handbook of Attachment, ed. Cassidy J, Shaver PR. New York: Guilford; 1999:89-111.

7. Hazan C, Shaver PR. Romantic love conceptualized as an attachment process. J Personality Social Psychol. 1987;52(3):511-24.

8. Mickelson KD, Kessler RC, Shaver PR. Adult attachment in a nationally representative sample. J Pers Soc Psychology. 1997;73(5):1092-106.

9. West ML, Sheldon-Kellor AE. Patterns of Relating: An Adult Attachment Perspective. New York: Guilford Press; 1994.

10. Klohnen EC, John OP. Working models of attachment: a theory-based prototype approach. Attachment Theory and Close Relationships, ed. Simpson JA, Rholes WS. New York: Guilford; 1998:115-40.

11. Özer Ü, Yıldırım EA, Erkoç ŞN. Major depresyon olgularında intihar düşünce ve davranışının bağlanma biçimi ile ilişkisi. Arch Neurosciatr. 2015;52(3):283-8.

12. Bartolomew K, Horowitz LM. Attachment styles among young adults: a test for four-category model. J Pers Soc Psychol. 1991;61(2):226-44.

13. Wilhelm K, Tietze T. Difficult doctor-patient interactions: applying principles of attachment-based care. Medicine Today. 2016;17(1-2):36-44.
14. Main M. Metacognitive knowledge, metacognitive monitoring, and singular (coherent) vs. multiple (incoherent) model of attachment: findings, and directions for future research. Attachment Across the Life Cycle, ed. Parkes CM, Stevenson-Hinde J, Marris P. Londra: Routledge; 1991:127-60.

15. Fonagy P, Steele H, Moran GS, Higgett AC. The capacity for understanding mental states: the reflective self in parent and child and its significance for security of attachment. Infant Ment Health J. 1991;12(3):201-18.

16. Lyons-Ruth $\mathrm{K}$, Block $\mathrm{D}$. The disturbed caregiving system: relations amongst childhood trauma, maternal caregiving, and infant affect, and attachment. Infant Mental Health J. 1996;17:257-75.

17. Adshead G. Psychiatric staff as attachment figures. Br J Psychiatry. 1998;172:64-9.

18. Blackwell B. Sick-role susceptibility. Psychother Psychosom. 1992;58:79-90.

19. Groves JE. Taking care of the hateful patient. N Engl J Med. 1978;298(16):883-7.

20. Lipowski ZJ, Somatization: the concept, and its clinical application. Am J Psychiatry. 1988;145(11):1358-68.

21. Dozier M. Attachment organization, and treatment use for adults with serious psychopathological disorders. Dev and Psychopathol. 1990;2(1):47-60.

22. Ciechanowski P, Katon W, Hirsch I. Attachment style and adherence in the diabetic patient. Psychosom Med. 1999;61(1):110.

23. Yilmaz Özpolat AG, Ayaz T, Konağ Ö, Özkan A. Attachment style and perceived social support as predictors of biopsychosocial adjustment to cancer. Turk J Med Sci. 2014;44(1):24-30.

24. Maunder RG, Hunter JJ. Attachment and psychosomatic medicine: developmental contributions to stress and disease. Psychosom Med. 2001;63(4):556-67. 